\title{
A educação em contextos bíblicos
}

\author{
The education in biblical contexts
}

\section{La educación en contextos bíblicos}

\author{
Antonio Carlos Soares dos Santos* \\ João Batista Ribeiro Santos ${ }^{* *}$
}

\begin{abstract}
RESUMO
Este artigo tem por objetivo abordar alguns princípios e postulados da educação textualizada na Bíblia judaica. Como forma de demonstrar o caráter formativo do judaísmo antigo presente no cristianismo, enunciamos aspectos da translação educativa no Novo Testamento. Nossa hipótese é que o processo ensino-aprendizagem principia no lar, mas sofre variadas transformações à medida que as instruções e códigos são reinterpretados em períodos específicos. Palavras-chave: Educação na Antiguidade; Escrituras Sagradas; memória de saberes; teologia da educação.
\end{abstract}

\begin{abstract}
This article aims to address some principles and postulates of textured education in the Jewish Bible. As a way of demonstrating the formative character of the ancient Judaism present in Christianity, we enunciate aspects of the educational translation in the New Testament. Our hypothesis is that the teaching-learning process begins in the home, but undergoes various transformations insofar as the instructions and codes are reinterpreted in specific periods.

Keywords: Education in Antiquity; Holy Scriptures; memory of knowledge; theology of education.

\section{RESUMEN}

Este artículo tiene por objetivo abordar algunos principios y postulados de la educación textualizada en la Biblia judia. Como forma de demostrar el carácter formativo del antiguo judaísmo presente en el cristianismo, enunciamos aspectos de la traslación educativa en el Nuevo Testamento. Nuestra hipótesis es que el proceso enseñanza-aprendizaje comienza en el hogar, pero pasa variadas transformaciones en la medida en que las instrucciones y códigos son reinterpretados en períodos específicos.

Palabras clave: Educación en la Antigüedad; Escrituras Sagradas; memoria de saberes; teología de la educación.
\end{abstract}

* Professor Tutor da Escola de Teologia da Universidade Metodista de São Paulo (UMESP). Mestre e doutorando em Ciências da Religião na Universidade Metodista de São Paulo (UMESP).

** Professor da Escola de Teologia da Universidade Metodista de São Paulo (UMESP). Mestre em História Política pela Universidade do Estado do Rio de Janeiro (UERJ), mestre e doutorando em Ciências da Religião na Universidade Metodista de São Paulo (UMESP). 


\section{Introdução}

A educação é relevante para a manutenção de qualquer grupo social, uma vez que uma comunidade firma a sua existência e desenvolvimento continuados apenas através da transmissão de sua memória e tradição acumuladas, poderes adquiridos e conceitos ideológicos para as gerações seguintes. A educação pode ser simplesmente definida como o processo de ensino e aprendizagem, a transmissão e aquisição de conhecimento e habilidades.

A necessidade de educação não era menos verdadeira para os antigos israelitas do que para qualquer um dos povos do antigo Oriente-Próximo (CERESKO, 2004). De fato, o registro do Primeiro Testamento indica repetidamente que o sucesso dos grupos sociais israelitas e a continuidade de sua cultura foram proporcionados pelo conhecimento de códigos legais traditados ou atualizados (Código da Aliança: Êxodo 20,22-23,19; Código Deuteronimista: Deuteronômio 12-26; Código da Santidade: Levítico 17-25). Assim, para assegurar sua prosperidade, crescimento e longevidade como o povo de YHWH, o mandamento a ser afixado no antigo Israel era de instrução, ensinando diligentemente seus filhos a amar a Deus, conhecer e obedecer a seus estatutos e ordenanças (Deuteronômio 6,1-9). Da mesma forma, o registro do Novo Testamento relaciona o sucesso da comunidade de Jesus de Nazaré, como uma comunidade de adoração, de "sal e luz", alcançando um mundo em que predomina os conflitos socioétnicos, para ensinar o amor (João 13,34-35; Efésios 4,14; 1Timóteo 1,10; Tito 2,1).

\section{Educação no mundo bíblico}

No antigo Oriente-Próximo, uma vez que a educação era básica para a existência de qualquer comunidade ou sociedade, seria natural que certos ideais fundantes, métodos e princípios pedagógicos fossem compartilhados entre diversos grupos sociais. O quadro não é diferente quando estudamos as práticas educacionais dos israelitas no contexto da formação humana para a vida, especialmente quando construídas em ambiente religioso.

O verbo hebraico lamad carrega todo um sentido educacional: a forma normal do verbo é o qal, e significa aprender, acostumar-se. Dois textos auxiliarão no melhor entendimento deste verbo na forma qal: ... uma nação não levantará a espada contra outra nação, nem aprenderão mais a guerra (Is 2.4); Jumenta selvagem, acostumada ao deserto... (Jr 2.24). Na forma Qal do verbo lamad, aprender é uma consequência normal da vida humana: É um aprendizado normal ou um acostumar-se (SIQUEIRA, 2011).

Podemos afirmar, portanto, que a educação no mundo do Primeiro Testamento estava enraizada na tradição religiosa e nos ideais teológicos. O 
objetivo da educação era a transmissão das tradições religiosas, juntamente com os costumes e valores da comunidade, e as habilidades litúrgicas e técnicas. O resultado proativo desse tipo de educação era um cidadão referencial, solidário à linhagem de parentesco, ao seu deus e ao rei, de caráter reto e produtivo na vida comunitária. Mais do que "pensadores livres" - educados liberalmente -, o resultado importante do sistema educacional para os antigos israelitas era a preservação da linhagem e suas tradições, deixando-as como legado; aqui não incluímos o bem material por ser este propriedade comunizada.

Para a maior parte, o método de ensino foi baseado no aprendizado cotidiano. Esta memorização dos acontecimentos diários foi realizada por recitação oral e escrita. O ensino disciplinado caracterizava a instrução educacional, com aulas ensinadas em horários fixos durante o dia e, muitas vezes, por um número definido de dias em um mês. Além de serem professores e mestres naturalmente, os pais (em casa) e os tutores (nas escolas formais) também serviam como mentores e modelos, ensinando pelo exemplo e estilo de vida.

O principal órgão de educação, tanto no Egito antigo quanto na Mesopotâmia, era o lar. Os pais e os anciãos do clã ou da família extensa eram responsáveis pela educação das crianças. A invenção dos sistemas de escrita e a crescente mudança para a urbanização deram origem a escolas especializadas associadas às principais instituições locais da época: o templo e o palácio. Considerando que a educação no lar se centrou na formação do cultivador e do artesão, além do desenvolvimento moral, as escolas do templo e do palácio foram concebidas para produzir alfabetizados, informados e líderes religiosos, sociopolíticos e administradores capazes (VÍLCHEZ LÍNDEZ, 1999, p. 29-36).

No entanto, mais surpreendente que essas semelhanças são as diferenças entre os ideais educacionais e práticas dos israelitas e os de seus vizinhos. É importante notar que esses distintivos educacionais israelitas estão diretamente relacionados a aspectos singulares da religião de YHWH.

No contexto hebraico, por exemplo,

Como nas demais civilizações antigas, os hebreus estavam impregnados da religiosidade transmitida pela Bíblia, livro sagrado com os fundamentos do judaísmo e que chegou até os tempos atuais. No entanto, significativas diferenças distinguem os hebreus dos demais povos (...) Outro aspecto do judaísmo é a importância dada a todo ofício, bem como o reconhecimento do valor da educação para o trabalho, o que atestam as seguintes citações: "A mesma obrigação tens de ensinar a teu filho um ofício como a de instruí-lo na Lei” (ARANHA, 2006, p. 50). 
Pode-se observar que algumas características do modelo educacional no antigo Israel não eram comuns às religiões do antigo Oriente-Próximo. Por exemplo, a paternidade de Deus na religião israelita trouxe uma sensação de intimidade à relação Criador-criatura e um sentido de propósito e urgência para a história humana. Assim, a educação enfatizou a importância de reconhecer e lembrar práticas e acontecimentos da Providência divina na história, traçando uma linha ritualística.

Uma das primeiras ênfases que se pode encontrar na Bíblia a respeito da educação um pouco mais ritualística está no Livro de Deuteronômio 6,4-9, que diz:

Ouve, Israel, o SENHOR, nosso Deus, é o único SENHOR. Amarás, pois, o SENHOR, teu Deus, de todo o teu coração, de toda a tua alma e de toda a tua força. Estas palavras que, hoje, te ordeno estarão no teu coração; tu as inculcarás a teus filhos, e delas falarás assentado em tua casa, e andando pelo caminho, e ao deitar-te, e ao levantar-te. Também as atarás como sinal na tua mão, e te serão por frontal entre os olhos. E as escreverás nos umbrais de tua casa e nas tuas portas.

A noção de que os israelitas eram um povo divinamente escolhido, encorajou fortes insinuações nacionalistas na religião e na educação hebraicas. Como ideal, os israelitas eram obrigados às exigências da santidade de Deus para permanecerem sua possessão especial, enquanto, ideologicamente, eles incumbiram a si instrução a todas as nações, dentro de uma santidade divina e redenção, como instrumento de luz de YHWH para as nações.

Também podemos destacar que a doutrina e o conceito de pecado caracterizam tanto a religião como a educação; isso introduziu o conceito de mediação na religião israelita, uma exigência para preencher a lacuna entre a crença em um Deus justo e sua criação decadente. Em adição, significava que a ciência e a sabedoria humanas eram falhas e limitadas; portanto, a iluminação divina era necessária para apreender certas verdades e a capacitação divina era necessária para a prática dessas mesmas verdades.

Especificamente, o processo de ensino-aprendizagem envolveu repetição disciplinada em observação, aprendizado experiencial (fazer), ouvir, recitar e imitar. Às vezes, orientação especial (estudo direcionado), bem como correção e advertência, faziam parte da experiência educacional. E, finalmente, as habilidades de pensamento crítico foram um importante resultado educacional, porque a aprendizagem tinha aplicação na vida diária.

$\mathrm{Na}$ história das famílias, as genealogias sempre seguem a linha paterna; as mulheres não são mencionadas, senão excepcionalmente. O marido é o senhor de sua esposa, seu baal. O pai tem autoridade total sobre os filhos, mesmo sobre os casados, se vivem com 
ele. Esse direito se estende até sobre a própria vida, como mostra Gn 38,24, onde Judá condena sua nora Tamar à morte, acusada de adultério (GORGULHO, 2005, p. 57).

Assim, a educação era essencialmente instrução quanto ao que dizia respeito a "guardar o caminho do Senhor" (Gênesis 18,19). A tradição mosaica resumiu os componentes básicos dessa obediência da aliança, em seu discurso de despedida aos israelitas, como amar a Deus, andar nos seus caminhos e guardar os seus mandamentos, estatutos e ordenanças (Deuteronômio 30,16). Mais tarde, o salmista condensou este conteúdo do pacto da educação do Primeiro Testamento na expressão "a lei do Senhor" (Salmo 119,1).

\section{Passos do processo educacional}

Desde que os israelitas reconheceram YHWH como o Deus da história, providencialmente ativo no curso de eventos humanos, a história também se tornou parte do conteúdo ou currículo da educação hebraica. A recitação e a lembrança festivas dos atos divinos na história humana eram instrutivas quanto à natureza de Deus e seus propósitos na criação. É claro que o exemplo primário desta trajetória histórica na educação hebraica é a festa dos Pães ázimos, posteriormente unificada com a festa da Páscoa como rememoração do êxodo do Egito (Êxodo 12,24-27; 13,11-16).

A casa era o principal lugar de instrução naquela sociedade. Enquanto o Primeiro Testamento enfatiza o papel do pai como professor, ambos os cônjuges são encarregados de treinar seus filhos (Provérbios 1,8; 6,20; 31,26). Uma vez que o antigo Israel era, em grande parte, uma sociedade de clãs, membros da família alargada, como avós, tias e tios, e até primos, também poderiam participar no processo educativo dentro do lar; essa interação social era aprofundada no matrimônio com o casamento de primos cruzados. O currículo da "escola em casa" era tanto religioso quanto vocacional, pois os pais e outros membros da família ensinavam as crianças "no temor do Senhor" (Provérbios 2,5) e uma habilidade comercial ou profissional, muitas vezes a do pai.

Em relação à prática da Educação infantil, a criança, até cinco anos de idade, tinha a educação informal em casa, em grande parte, sob a responsabilidade da mãe, de uma enfermeira ou de um tutor masculino. "As crianças recebiam os primeiros elementos de uma instrução, sobretudo moral, tanto do pai como da mãe (Provérbios 1,8; 6,20; 23,22). No seio da família, eram também transmitidas a fé, a história, a lei e as tradições da nação" (VAUX, 2003, p. 72-73).

Um jovem entre cinco e vinte geralmente trabalhava com seu pai como aprendiz, aprendendo uma vocação. Sem dúvida, a instrução dos pais nas tradições continuou durante aqueles anos, reforçada pela associação com a 
família extensa e envolvimento no ritual de culto comunitário. No judaísmo antigo, os filhos do sexo masculino entre as idades de cinco e vinte anos normalmente frequentavam escolas de sinagoga e eram treinados por meio da Torah, da Mishnah e do Talmud. Aos vinte anos de idade - cerca de oito anos após celebrar o Bar Mitzvah -, um jovem estava pronto como indivíduo e, aos trinta anos, poderia assumir uma posição oficial de reconhecida responsabilidade.

As mulheres jovens eram educadas para as habilidades domésticas culturalmente aceitáveis. Havia profissões que estavam abertas às mulheres, incluindo as de enfermeira e parteira, cozinheira, tecelã, perfumista, cantora. Em certos casos, as mulheres assumiram posições proeminentes de liderança, como a administradora da justiça Deborah (Juízes 4,4-5) e a reconhecida linguista Hulda (2 Reis 22,14-15). É provável que as mulheres aristocráticas de Jerusalém recebessem algum tipo de escolaridade formal semelhante à de seus companheiros masculinos, uma vez que faziam parte do sistema político oficial. Destarte, há quem afirme que a prostituição, tanto a sexual quanto a cultual, continuou sendo uma fonte de emprego e, ao mesmo tempo, de discriminação para as mulheres nesta sociedade antiga (GANCHO, 1970, p. 248-254).

\section{A família na época do cristianismo formativo: mínimas peculiaridades}

A busca por informações da vida familial na Antiguidade Clássica passa pela contextualização do casamento. Existiam, inicialmente, dois tipos de casamento. O casamento de membros da aristocracia, "com a mão", modelo em que se dizia que a mulher era tirada do poder do pai e colocada na mão do marido; nesse caso, ela mantinha a posição de "filha", levava consigo um dote e tinha o mater familias; esse casamento prevaleceu até a época do imperador Nero. Com o passar do tempo, criou-se o casamento por concordância voluntária (GOODY, 2011, p. 486-487, 499 ss.).

$\mathrm{Na}$ Roma antiga, nem todos se casavam no sentido formal, pois o casamento tinha um único objetivo, transmitir o patrimônio aos descendentes. Mais tarde, os plebeus (pobres) começaram a casar-se, fato que pode ter contribuído para a afeição entre pais e filhos. Os sentimentos foram expressos nos memoriais fúnebres, que revelam, essencialmente, mais dedicatórias dos pais aos filhos do que o contrário.

Em Roma, a idade de casamento dos homens parece ter sido por volta dos 25 aos 30 anos, para a maioria da população; as mulheres casavam-se mais cedo, entre os 15 e 25 anos. Na aristocracia, os casamentos eram mais 
precoces; a princípio, não se admitia o divórcio e a legitimidade dos filhos era importante. Entre os pobres, a legitimidade dos filhos era menos importante.

Quando nos referimos à família israelita, há de se compreender que pertence a uma estrutura tipicamente patriarcal - casa paterna. Grande parte da compreensão do Novo Testamento sobre a educação é simplesmente assumida a partir da prática do Primeiro Testamento e do judaísmo antigo. Por exemplo, a família continua a ser o principal contexto para a educação, com a proeminência também dada à igreja como a família alargada ou comunidade de fé. Do mesmo modo, o objetivo de educar a pessoa, a mente e o caráter inteiros transpõe a prática hebraica no Primeiro Testamento. Até mesmo a metodologia de incutir informação e extrair ou desenvolver os talentos e habilidades inatas do aluno encontra aqui seu precedente.

O nome da mãe de Jesus de Nazaré é Maria, ou Mariam, nome carregado de simbolismo, por ser o mesmo nome da irmã de Moisés. O evangelho de Marcos nunca menciona o nome do pai de Jesus; em sua memória mais antiga, na qual apresenta a família, ele cita a mãe e os irmãos (Marcos 3,21; 3,31). Mateus $(13,55)$ fala de "filho de carpinteiro", Lucas $(4,22)$ e João $(6,42)$ falam em "filho de José". Considerando que Jesus tem um nascimento virginal, isto é, nascido de Deus, José é o pater (Mateus 1,20, 24-25).

Jesus é a versão grega do nome hebraico do conquistador hebreu Josué, um nome comum na época. Quanto ao lugar de nascimento, as "narrativas da infância" de Mateus $(2,1)$ e Lucas $(2,4-7)$ indicam-no em Belém; mas Marcos $(1,9)$, o relato mais antigo, fala de Nazaré. No evangelho de João, não há relato da infância, mas o evangelista diz que Jesus vem de Nazaré (João 1,45-46). Em uma citação de Mateus $(21,11)$, a multidão diz que Jesus é de Nazaré. Jesus era de uma família numerosa - Mateus (13,55-56) é o mais enfático quanto a isso. A partir do segundo século, os textos cristãos e alguns pais da Igreja começaram a afirmar que os filhos eram de um primeiro casamento de José (BARBAGLIO, 2011, p. 119 ss.).

Segundo alguns exegetas, em Mateus 19,12 (Pois existem eunucos os quais do ventre da mãe foram gerados assim, e existem eunucos os quais foram feitos eunucos a si próprios por causa do reino dos céus. O que é capaz de admitir que admita.) está a resposta de Jesus aos possíveis gracejos por ele estar na "segunda idade" ainda solteiro. Neste caso, Jesus não segue nem a tradição templar, nem a tradição campesina de suprimento de mão de obra, mas a tradição dos essênios, que recusavam o matrimônio para dedicar-se à fé.

A família é representativa para o cristianismo formativo; as comunidades até são designadas de "casa de Deus" (1Timóteo 3,15) e seus membros como membros da casa de Deus (Efésios 2,19). No período imperial romano, 
existiam várias associações voluntárias que ajudavam as famílias. Eram denominadas de colégio (de sacerdotes e magistrados), corpo, cúria (ordem política e religiosa), partido, confraria, éranos (associação de socorro) etc. Mantinham ramos da atividade artesanal e da atividade manufatureira (padeiros, barqueiros etc.), bem como comerciantes e negociantes, e sociedades funerárias de integrantes das camadas empobrecidas. Escravos e mulheres podiam ser encontrados mais facilmente nas associações religiosas (STEGEMANN; STEGEMANN, 2004, p. 313 ss.).

As refeições em conjunto, chamadas pelos cristãos de "partir o pão" (Atos 2,42, 46) são reflexo das refeições em conjunto, existentes nas economias domésticas antigas. Era uso corrente que os peregrinos praticassem a caridade em Jerusalém; com esse propósito, o templo gastava parte do segundo dízimo e o produto das árvores e vinhas de quatro em quatro anos. O dízimo de uma semana do terceiro e sexto ano, entregue pelos pobres, era redistribuído aos pobres, viúvas e prosélitos. Entre os essênios, em cada cidade havia um funcionário da ordem encarregado de prover os irmãos necessitados de roupas e outras coisas necessárias (JEREMIAS, 1985, p. 183 ss.). O livro dos Atos dos Apóstolos mostra que os cristãos faziam algo semelhante.

Os cristãos mantinham o "prato dos pobres", que era distribuído todos os dias aos pobres em trânsito ou itinerantes; compunha-se de pão, favas, frutas, na Páscoa era acrescentado o vinho; e a "cesta dos pobres", distribuída todas as semanas aos pobres da cidade, compunha-se de alimento e roupa. Essas distribuições eram centralizadas em um único lugar, na casa de oração.

Quanto à educação, podia-se receber educação (Paideia, pais, paidos, formação de meninos; humanitas, humanização) em escolas públicas ou por tutoria. A escola pública, dirigida quase exclusivamente aos homens (as mulheres costumavam ficar em casa), funcionava em qualquer local, mas em geral nos ginásios ou liceu.

A aristocracia educava os membros da família preferencialmente por meio de tutores particulares; se a família era romana, preferia tutor grego. A educação era, no entanto, privilégio da gente rica. Orientava-se ao preparo para a vida pública e para as funções que se haveriam de exercer nela, especialmente na política e na administração, além da retórica e das artes plásticas. Em adição, é razoável salientar que se liam sempre os poetas atualmente clássicos, dos quais o apóstolo Paulo cita três: Arato, nascido em Solos, na Cilícia, viveu entre 310-245 a.C. (Atos 17,28); Menandro, nasceu em Atenas e viveu entre 342-291 a.C. (1 Coríntios 15,33); e Epimênides, nasceu em Creta em data incerta, c. século VI a.C. (Tito 1,12; cf. Atos 17,16). 
O Novo Testamento nos ensina diversas lições pedagógicas e teológicas importantes para a aplicação na educação cristã contemporânea. Primeiro, a educação atende a toda pessoa: corpo, emoções e vontade. Também, o Novo Testamento entende a educação como um processo tanto de influir (transmitir informações ao aluno) quanto de extrair (extrair o aprendizado do aluno ou autodescoberta).

\section{Enfim...}

Teologicamente, a prática da educação descrita nas textualizações do Primeiro e Novo Testamento resultou na bênção do pacto de YHWH, em que se postula para os fieis da mesma divindade. Essas bênçãos divinas incluíam a autonomia política e a segurança, e a prosperidade agrícola e econômica (Levítico 26,1-8). Sociologicamente, a prática da educação facilitou a assimilação na comunidade de fé e assegurou a estabilização dessa comunidade, porque o princípio de "fazer justiça" permeava a sociedade (Levítico $19,15,18)$. Nos contextos sociorreligiosos, a prática da educação sustentou o relacionamento do pacto com sua religião, através da obediência e ritual apropriado, o que, presume-se, motivou o favor e a presença de Deus com Israel (Levítico 26,9-12).

Em última análise, a educação bíblica é instrução em um estilo de vida. Por esta razão, o apóstolo Paulo lembrou a seu discípulo Timóteo: "você sabe tudo sobre o meu ensinamento, o meu modo de vida continua no que você aprendeu” (2 Timóteo 3,10; 3.14).

\section{Referências bibliográficas}

ARANHA, Maria Lúcia de Arruda. História da educação e da pedagogia: geral e Brasil. 3. ed. São Paulo: Moderna, 2006.

BARBAGLIO, Giuseppe. Jesus, bebreu da Galileia. São Paulo: Paulinas, 2011.

CERESKO, Anthony R. A sabedoria no Antigo Testamento: espiritualidade libertadora. Tradução de Adail Ubirajara Sobral e Maria Stela Gonçalves. São Paulo: Paulus, 2004.

GANCHO, C. Primogênito. In: DIEZ-MACHO, Alejandro; BARTINA, Sebastian. Enciclopedia de la Biblia. Barcelona: Ediciones Garriga, 1970.

GOODY, Jack. O oriental, o antigo e o primitivo: os sistemas de casamentos e a família nas sociedades pré-industriais da Eurásia. São Paulo: Edusp, 2008.

JEREMIAS, Joachim. Jerusalém no tempo de Jesus. 3. ed. São Paulo: Paulus, 1995.

SIQUEIRA, Tércio Machado. Ensinar e aprender na Bíblia. Caminhando, São Bernardo do Campo, vol. 16, n. 1, p. 71-77, jan-jun, 2011.

STEGEMANN, Ekkehard W.; STEGEMANN, Wolfgang. História social do protocristianismo. São Paulo; São Leopoldo: Paulus; Sinodal, 2004. 
VAUX, Roland de. Instituições de Israel no Antigo Testamento. Tradução de Daniel de Oliveira. São Paulo: Teológica, 2003.

VÍLCHEZ LÍNDEZ, José. Sabedoria e sábios em Israel. Tradução de José Benedito Alves. São Paulo: Loyola, 1999.

Submetido em: 11-5-2017

Aceito em: 21-6-2017 